\title{
Utility of 2-Pyridine Aldoxime Methyl Chloride (2-PAM) for Acute Organophosphate Poisoning: A Systematic Review and Meta-Analysis
}

\author{
Adam Blumenberg ${ }^{1,2} \cdot$ Roshanak Benabbas $^{1,2}$ - Ian S. deSouza ${ }^{1,2}$ - Alyssa Conigliaro ${ }^{2}$. \\ Lorenzo Paladino $^{1,2} \cdot$ Elliot Warman $^{1} \cdot$ Richard Sinert $^{1,2} \cdot$ Sage W. Wiener ${ }^{1,2}$
}

Received: 19 July 2017 /Revised: 23 October 2017 / Accepted: 26 October 2017 / Published online: 11 December 2017

(C) American College of Medical Toxicology 2017

\begin{abstract}
Organophosphates (OP) account for the majority of pesticide-related unintentional or intentional poisonings in lower- and middle-income countries. The therapeutic role of atropine is well-established for patients with acute OP poisoning. The benefit of adding 2-pyridine aldoxime methyl chloride (2-PAM), however, is controversial. We performed a systematic review and meta-analysis of available randomized controlled trials (RCT) to compare 2-PAM plus atropine in comparison to atropine alone for acute OP poisoning. We searched PubMed, EMBASE, and SCOPUS up to March 2017. The Cochrane review handbook was used to assess the risk of bias. Data were abstracted and risk ratios (RR) were calculated for mortality, rate of intubation, duration of intubation, intermediate syndrome, and complications such as hospital-acquired infections, dysrhythmias, and pulmonary edema. We found five studies comprising 586 patients with varying risks of bias. The risk of death $(\mathrm{RR}=1.5,95 \% \mathrm{CI} 0.9-2.5)$; intubation $(\mathrm{RR}=1.3$, 95\% CI 1.0-1.6); intermediate syndrome $(\mathrm{RR}=1.6,95 \% \mathrm{CI}$ 1.0-2.6); complications ( $\mathrm{RR}=1.2,95 \% \mathrm{CI} 0.8-1.8)$; and the duration of intubation (mean difference $0.0,95 \% \mathrm{CI}-1.6-1.6$ )
\end{abstract}

The original version of this article was revised: The names of coauthors Roshanak Benabbas and and Ian S. deSouza were given incorrectly (as "Roshnak Benabbas" and "Ian de Souza", respectively) in this article as originally published.

Electronic supplementary material The online version of this article (https://doi.org/10.1007/s13181-017-0636-2) contains supplementary material, which is available to authorized users.

Sage W. Wiener

sagewiener-em@yahoo.com

1 Department of Emergency Medicine, Downstate Medical Center, State University of New York, Albany, NY, USA

2 Department of Emergency Medicine, Kings County Hospital Center, 451 Clarkson Avenue, Brooklyn, NY 11203, USA were not significantly different between the atropine plus 2PAM and atropine alone. Based on our meta-analysis of the available RCTs, 2-PAM was not shown to improve outcomes in patients with acute OP poisoning.

Keywords Organophosphates $\cdot$ Poisoning $\cdot$ Pralidoxime compounds · Oximes

\section{Introduction}

Organophosphate (OP) compounds are used primarily as pesticides in agricultural settings but have also been developed into nerve agents such as sarin and VX. Organophosphates account for the majority of pesticide-related unintentional or intentional poisonings in lower- and middle-income countries [1]. The World Health Organization estimates that about 3 million poisonings (1 million unintentional and 2 million intentional) involving OP pesticides occur annually worldwide resulting in 220,000 deaths [2]. Seventy percent of unintentional poisonings are related to occupational exposures in Sri Lanka [3]. Intentional poisonings comprise approximately $60-70 \%$ of pesticide poisonings in Malaysia, Indonesia, and Thailand 4.

Use of OP-containing nerve gas is also an ongoing concern in present-day conflicts. Organophosphates were first developed for warfare in Nazi Germany and have since been deployed multiple times with devastating effects: Iran-Iraq war (1980-1988) by Saddam Hussein [5, 6] and Syrian conflicts in 2013 [7,8] and 2017 [9]. These agents were also used in a terrorist attack in the Tokyo subway in 1995 [10] and have been implicated more recently in the assassination of Kim Jung Nam, the half-brother of Kim Jung Un [11]. It is crucial for clinicians to understand the optimal treatment for acute OP poisonings, not only because of the widespread use of OP in 
agriculture but also due to the potential threat of chemical warfare with OP-containing agents.

Organophosphates phosphorylate the serine hydroxyl group of acetylcholinesterase to inactivate the enzyme. Acetylcholine then accumulates within the nervous system overstimulating both the muscarinic and nicotinic receptors leading to a wide range of clinical effects: (1) salivation, lacrimation, urination, diarrhea, gastrointestinal distress, emesis (SLUDGE); bronchorrhea, bronchoconstriction, and bradycardia (muscarinic); (2) muscle fasciculations, weakness, and diaphragmatic paralysis (nicotinic); and (3) restlessness, dysarthria, tremor, altered mentation, psychosis, and seizure (central nervous system). The "intermediate syndrome" (IMS) may occur from 24 to $96 \mathrm{~h}$ after resolution of the cholinergic toxidrome and is characterized by respiratory paralysis, cranial neuropathy, proximal limb weakness, and hyporeflexia. Mortality due to OP poisoning is typically a result of respiratory failure.

The treatment of OP poisoning includes decontamination, supportive care, and the antidotes, atropine and oximes. Atropine, the initial antidote in organophosphate poisoning, competitively inhibits acetylcholine at the muscarinic synapses making this agent the primary antidote in OP poisoning. Oximes such as pralidoxime chloride, also known as 2pyridine aldoxime methyl chloride (2-PAM), reactivate acetylcholinesterases by removing the phosphoryl group to restore transmission at both nicotinic and muscarinic synapses. The addition of oximes to atropine in OP poisonings has the therapeutic potential to augment atropine's effect at the muscarinic synapse with the additional benefit of reactivating acetylcholinesterases which may subsequently catalyze excess acetylcholine at the nicotinic synapses. Yet, the benefit of adding oximes is controversial in OP poisoning. This mechanism has been demonstrated by in vitro studies [12], but the benefit of oximes for in vivo OP poisoning is less apparent. Previous systematic reviews of oxime studies have reported inconclusive results $[13,14]$ and possible harm. [15, 16]. Through the use of a systematic review/meta-analytic approach, we incorporate additional data from a large number of patients to clarify the benefit of 2-PAM for treating patients with acute OP poisoning.

\section{Methods}

\section{Study Design}

We conducted a systematic review and meta-analysis to examine the effectiveness of 2-PAM in OP pesticide poisoning. This systematic review and meta-analysis was conducted using the Preferred Reporting Items for Systematic Review and Metaanalyses (PRISMA) guidelines. 17 Methods of the analysis and inclusion criteria were specified in advance. The protocol for this systematic review can be accessed in PROSPERO 18 with registration number: CRD42017058888.

Fig. 1 Study selection process

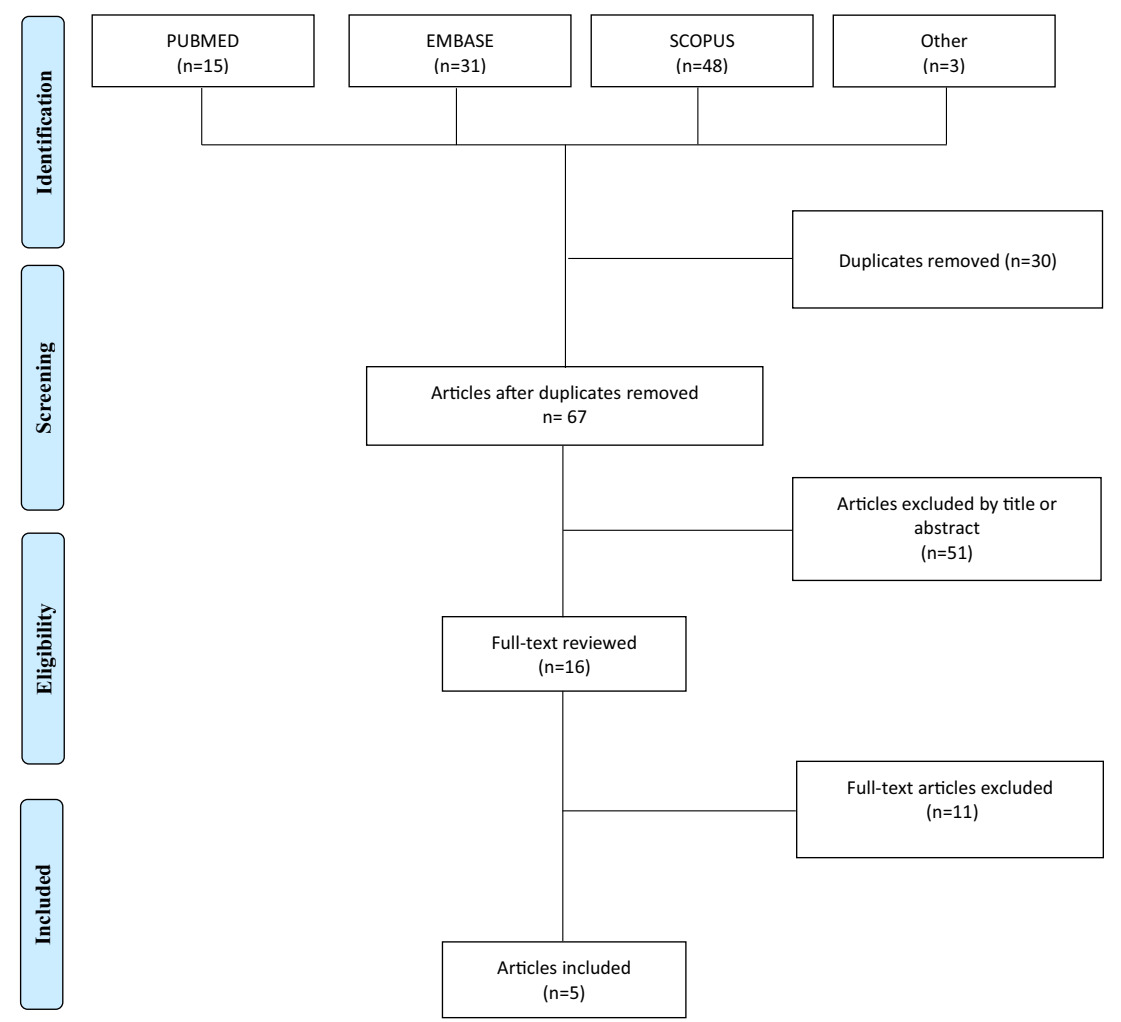


Table 1 Description of the included studies

\begin{tabular}{llll}
\hline Study $\quad$ Design Participants & Intervention* & Mortality \% (95\% \\
\hline
\end{tabular}

\begin{tabular}{|c|c|c|c|c|}
\hline Cherian et al. [21] & RCT & $\begin{array}{l}\text { - Inclusion: } \\
\text { Signs and symptoms warranting hospital } \\
\quad \text { admission } \\
\text { Serum pseudocholinesterase level }<50 \% \\
\quad \text { normal } \\
\text { - Exclusion: } \\
\text { Presenting after } 48 \mathrm{~h} \\
\text { Ingestion of carbamates } \\
\text { Medical comorbidities } \\
\text { Pregnancy } \\
\text { - Sample size: } 110 \\
\text { - Mean age: } \\
28 \text { ( } \pm 10.1) \text { years in treatment group } \\
26 \text { ( } \pm 10.3) \text { years in control group } \\
\cdot \text { Sex: } \\
75 \% \mathrm{M} \text { in treatment group } \\
62 \% \mathrm{M} \text { in control group }\end{array}$ & $\begin{array}{l}\text { Pralidoxime chloride [ } 12 \mathrm{~g} \text { infusion for } 3 \text { days] } \\
\text { Placebo: [NS infusion for } 3 \text { days] } \\
\text { Atropine dosage: titrated to patient signs and } \\
\quad \text { symptoms until atropinization** }\end{array}$ & $\begin{array}{l}\text { Treatment group: } \\
29 \text { (19-42) } \\
\text { Placebo group: } \\
5(1.0-15)\end{array}$ \\
\hline Cherian et al. [22] & $\mathrm{RCT}$ & $\begin{array}{l}\text { - Inclusion: } \\
\text { Moderate to severe poisoning using Namba } \\
\text { scale } \\
\text { - Exclusion: Not specified } \\
\text { - Sample size: } 21 \\
\text { - Age: Not specified } \\
\text { - Sex: Not specified }\end{array}$ & $\begin{array}{l}\text { Pralidoxime chloride 2-PAM [ } 12 \mathrm{~g} \text { infusion } \\
\text { per day for } 3 \text { days in severe cases, } \\
4 \mathrm{~g} / \text { day for } 3 \text { days for moderate cases] } \\
\text { Placebo [NS infusion for } 3 \text { days] } \\
\text { Atropine dosage: titrated to patient signs and } \\
\text { symptoms until atropinization** }\end{array}$ & $\begin{array}{l}\text { Treatment group: } \\
1(0.0-43) \\
\text { Placebo group: } \\
1(0.0-40)\end{array}$ \\
\hline $\begin{array}{l}\text { Eddleston et al. } \\
\text { [23] }\end{array}$ & $\mathrm{RCT}$ & $\begin{array}{l}\text { - Inclusion: } \\
\text { Self-poisoning } \\
\text { - Exclusion: } \\
\text { Age }<14 \text { years } \\
\text { Pregnancy } \\
\text { - Sample size: } 235 \\
\text { - Median age: } \\
31(22-48) \text { years in treatment group } \\
29(23-42) \text { years in control group } \\
\text { - Sex: } \\
79 \% \mathrm{M} \text { in treatment group } \\
81 \% \mathrm{M} \text { in control group }\end{array}$ & $\begin{array}{l}\text { Pralidoxime chloride [ } 2 \mathrm{~g} \text { loading dose over } \\
20 \mathrm{~min} \text {, then } 0.5 \mathrm{~g} / \mathrm{h} \text { until max dose of } \\
7 \text { days or until atropine is no more required } \\
\text { for } 12-24 \mathrm{~h} \text { ] } \\
\text { Placebo [NS loading dose and infusion] } \\
\text { Atropine dosage: Not specified }\end{array}$ & $\begin{array}{l}\text { Treatment group: } \\
25 \text { (18-33) } \\
\text { Placebo group: } \\
16(10-24)\end{array}$ \\
\hline Banerjee et al. [24] & RCT & $\begin{array}{l}\text { - Inclusion: } \\
\text { Presenting within } 24 \mathrm{~h} \text { of poisoning } \\
\text { - Exclusion: } \\
\text { Age }<12 \text { years } \\
\text { Ingestion of carbamates } \\
\text { - Sample size: } 120 \\
\text { - Mean age: } \\
35( \pm 10) \text { years in treatment group } \\
34( \pm 9) \text { years in control group } \\
\text { - Sex: } \\
38 \% \mathrm{M} \text { in treatment group } \\
43 \% \mathrm{M} \text { in control group }\end{array}$ & $\begin{array}{l}\text { Pralidoxime chloride }[1 \mathrm{~g} \text { IV every } 6 \mathrm{~h} \text { for } \\
5 \text { days] } \\
\text { Placebo not specified } \\
\text { Atropine dosage: } 2 \mathrm{mg} \text { IV stat and then } 2 \mathrm{mg} \\
\quad \text { IV Q5-10 min until atropinization*** }\end{array}$ & $\begin{array}{l}\text { Treatment group: } \\
8 \text { (10-31) } \\
\text { placebo group: } \\
13 \text { (7-24) }\end{array}$ \\
\hline Syed et al. [25] & $\mathrm{RCT}$ & $\begin{array}{l}\text { - Inclusion: } \\
\text { Grade } 2 \text { or } 3 \text { poisoning using Bardin grade } \\
\text { - Exclusion: } \\
\text { Age }<14 \text { or }>60 \text { years } \\
\text { Pregnancy } \\
\text { Ingestion of carbamates } \\
\text { Chronic medical conditions } \\
>12 \text { h past from ingestion } \\
\text { - Sample size: } 100 \\
\text { - Mean Age: } \\
29( \pm 11) \text { years in treatment group } \\
28( \pm 10) \text { years in control group }\end{array}$ & $\begin{array}{l}\text { Pralidoxime chloride }[30 \mathrm{mg} / \mathrm{kg} \text { loading dose } \\
\text { over } 30 \mathrm{~min} \text { then } 8 \mathrm{mg} / \mathrm{kg} / \mathrm{h} \text { infusion } \\
\text { for max } 7 \text { days] } \\
\text { Placebo [NS] } \\
\text { Atropine dosage: } \\
\text { 2-3 mg IV stat, then dose doubled until } \\
\text { atropinization** }\end{array}$ & $\begin{array}{l}\text { Treatment group: } \\
26 \text { (16-40) } \\
\text { Placebo group: } \\
8(17-42)\end{array}$ \\
\hline
\end{tabular}


Table 1 (continued)

\begin{tabular}{llc}
\hline Study & Intervention* & Mortality \% (95\% \\
CI)
\end{tabular}

NS normal saline, $M$ male, $F$ female

*All patients received atropine

$* *$ Pulse rate $=100 / \mathrm{min}$, midsize pupils, normal bowel sound, clear lungs, and no signs of atropine intoxicity

$* * *$ Pulse rate $>80 / \mathrm{min}$, midsize pupils, systolic blood pressure $>80 \mathrm{mmHg}$, clear lungs, and dry axilla

\section{Search Strategy}

In conjunction with a medical librarian, three investigators independently searched the medical literature from 2009 to March 2017 in PubMed, EMBASE, and SCOPUS (gray literature). We started our search at 2009 when the last Cochrane review [13] ended their search. To ensure that no pertinent studies were missed, we reviewed the search strategy used in the Cochrane review [13] with the help of a medical librarian. The studies utilized in the Cochrane review [13] were also included in this systematic review. We searched the bibliographies of the included articles for additional studies not found in our database search. The terms insecticides, organophosphates, oximes, and randomized controlled trial were searched under MeSH headings while 2-PAM was searched under Supplementary Concept and all fields. The study type was limited to randomized controlled trials (RCTs) in the English language, and study subjects were limited to humans. The full search strategy can be seen in more detail in Appendix 1 . Narrative reviews, case reports, or laboratory studies were not included.

\section{Criteria for Considering Studies for this Review}

The PICO format was used for this systematic review to answer the question, "Does the addition of 2-PAM to atropine reduce mortality, hospital length of stay, rate for intubation or intermediate syndrome in organophosphate insecticide poisoning?" We compared results of papers reporting treatment of OP poisoning with and without the addition of 2PAM. Unintentional and intentional poisonings were included in the review.

Patients: Patients with acute OP poisoning.

Intervention: Addition of 2-PAM to treatment of OP poisoning.

Comparison: Atropine alone, without the addition of 2PAM.

Outcomes: Mortality, rate of intubation, duration of intubation, hospital length of stay, complication rate, and development of intermediate syndrome.

\section{Data Abstraction}

Two authors (AC, RB) independently selected articles from the combined PubMed/EMBASE/SCOPUS searches for fulltext review. Each reviewer independently selected potentially eligible studies before both authors agreed on the list of studies for full-text review. Differences in study selection were resolved by consensus. Upon full-text review of the articles, the methods sections were searched for the inclusion and exclusion criteria to determine which studies to include in our systematic review. Differences were resolved by consensus after discussion and adjudication.

\section{Data Analysis}

Risk ratios (RR) were calculated based on construction of two by two tables for each included study. We combined data for summary estimates of outcomes using a random-effects model with RevMan 5.3 software [19]. Inter-study heterogeneity was assessed for pooled estimates of risk ratios using the DerSimonian-Laird random effect model [21].

\section{Quality Assessment}

Three authors (EW, AC, and RB) assessed the risk of bias of the included studies according to the Cochrane review handbook suggestions [20]. The tool allows for risk assessment of the included studies in six domains of bias:

- Selection bias: the potential to have systematic differences between baseline characteristics of the groups that are being compared. This bias is evaluated based on two criteria. Random sequence generation, the ability to produce comparable groups based on generation of randomized sequences; and allocation concealment, the ability to prevent foreknowledge of allocations prior to group assignment.

- Performance bias: the potential to have systematic differences between groups in the care that is provided, or in exposure to factors other than the interventions of interest. 


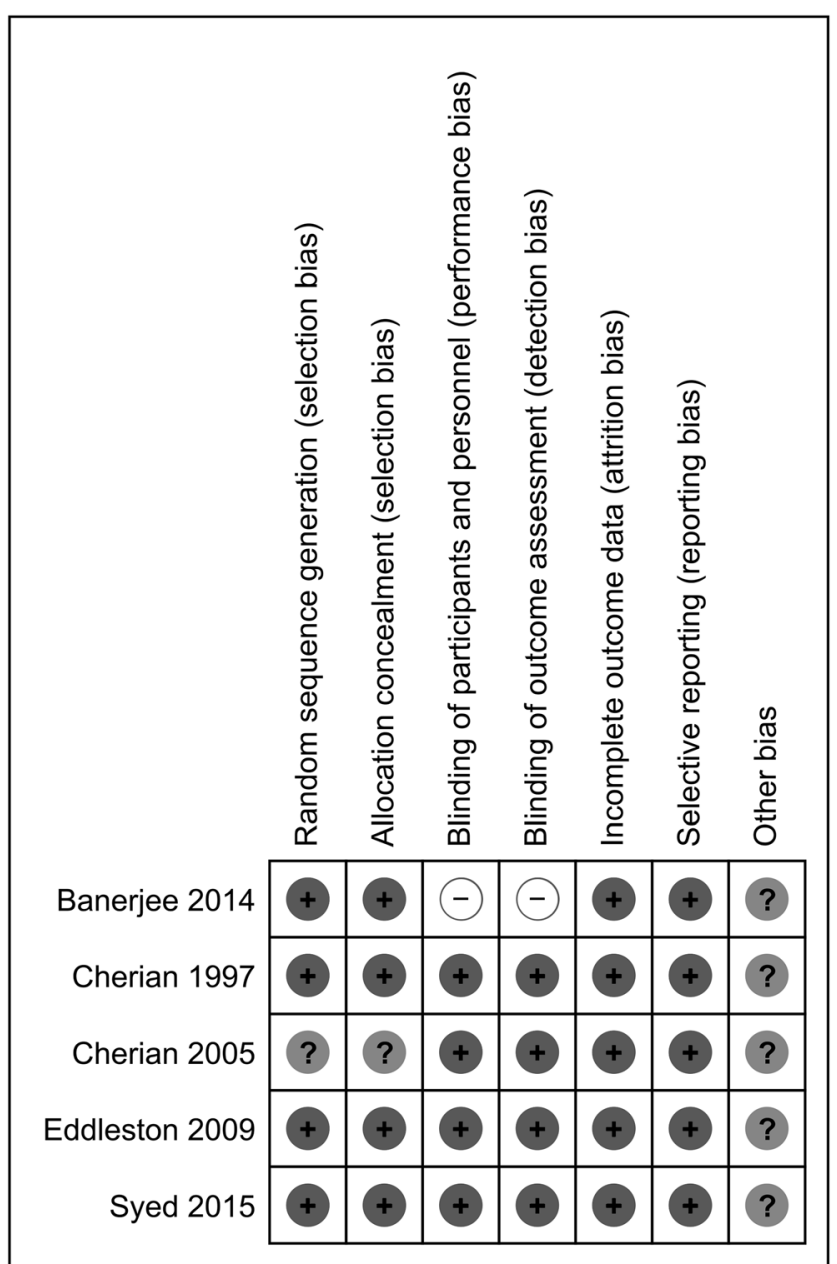

Fig. 2 Quality assessment

- Detection bias: the potential to have systematic differences between groups in how outcomes are determined.

- Attrition bias: the potential to have systematic differences between groups due to withdrawals from a study.

- Reporting bias: the potential to have systematic differences between reported and unreported findings as a result of selective outcome reporting.

- Other bias: any other important concerns about bias not addressed through the other domains in the tool.
Each study is then classified as high, low, or unclear risk within each of the domains. Intra-class correlation coefficient was calculated to measure inter-rater reliability between the three

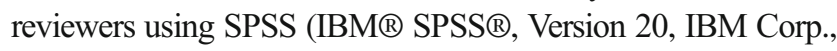
Armonk, NY). All disagreements were resolved by consensus.

\section{Results}

\section{Description of Included Studies}

PubMed, EMBASE, and SCOPUS searches identified 64 citations after removal of the duplicates. Three studies [21-23] were added from the Cochrane Review by Buckley et al. [13]. A total of five studies [21-25] $(N=586)$ were included. See Fig. 1 for the study selection process and Table 1 for description of individual studies.

The inclusion and exclusion criteria were not uniform across included studies. While Banerjee et al. [24] and Eddlestone et al. [23] included all patients regardless of the severity of their symptoms, Cherian et al. [21, 22] Syed et al. [25] only included those with moderate to severe poisoning. While four studies $[21,22,24,25]$ included both intentional and unintentional poisoning, one study [23] only included patients with self-poisoning. Three studies $[21,24,25]$ excluded patients with carbamate poisoning and three studies [21, 23, 25] excluded pregnant patients. While atropine was used at the standard of care dose and frequency (titrated by symptoms) in all trials, the dose and frequency of 2-PAM varied among the studies (Table 1).

\section{Quality Assessment}

The initial agreement between the three reviewers was substantial with intra-class correlation coefficient of 0.81 (95\% CI $0.70-0.89)$. All disagreements were resolved by consensus, and all authors agreed $100 \%$ with the final assessment (Fig. 2). Four studies [21, 23-25] were low-risk for selection bias based on random sequence generation; Cherian [22] was determined to be of unclear risk as it did not indicate its method of sequence generation. Cherian [22] was determined to be of unclear risk of selection bias as they did not indicate their

\begin{tabular}{|c|c|c|c|c|c|}
\hline \multirow[b]{2}{*}{ Study or Subgroup } & \multicolumn{2}{|c|}{ Treatment group (2-PAM) } & \multicolumn{2}{|c|}{ Placebo group } & \multirow[b]{2}{*}{ Weight } \\
\hline & Events & Total & Events & Total & \\
\hline Cherian 1997 & 16 & 55 & 3 & 55 & $13.7 \%$ \\
\hline Cherian 2005 & 1 & 10 & 1 & 11 & $3.5 \%$ \\
\hline Eddleston 2009 & 30 & 121 & 18 & 114 & $33.2 \%$ \\
\hline Banerjee 2014 & 11 & 60 & 8 & 60 & $21.5 \%$ \\
\hline Syed 2015 & 13 & 50 & 14 & 50 & $28.1 \%$ \\
\hline Total $(95 \% \mathrm{Cl})$ & & 296 & & 290 & $100.0 \%$ \\
\hline Total events & 71 & & 44 & & \\
\hline \multicolumn{6}{|c|}{ Heterogeneity: $\mathrm{Tau}^{2}=0.13 ; \mathrm{Chi}^{2}=6.89, \mathrm{df}=4(\mathrm{P}=0.14) ; \mathrm{I}^{2}=42 \%$} \\
\hline
\end{tabular}

Fig. 3 Mortality
Risk Ratio

M-H, Random, 95\% Cl Year

$5.33[1.65,17.27] 1997$

$1.10[0.08,15.36] 2005$

$1.57[0.93,2.66] 2009$

$1.38[0.60,3.18] 2014$

$0.93[0.49,1.77] 2015$

$1.54[0.92,2.56]$

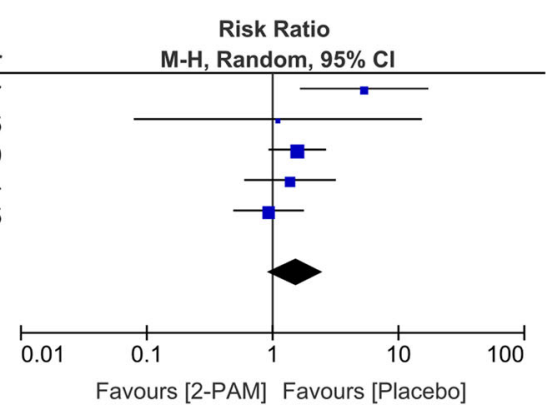




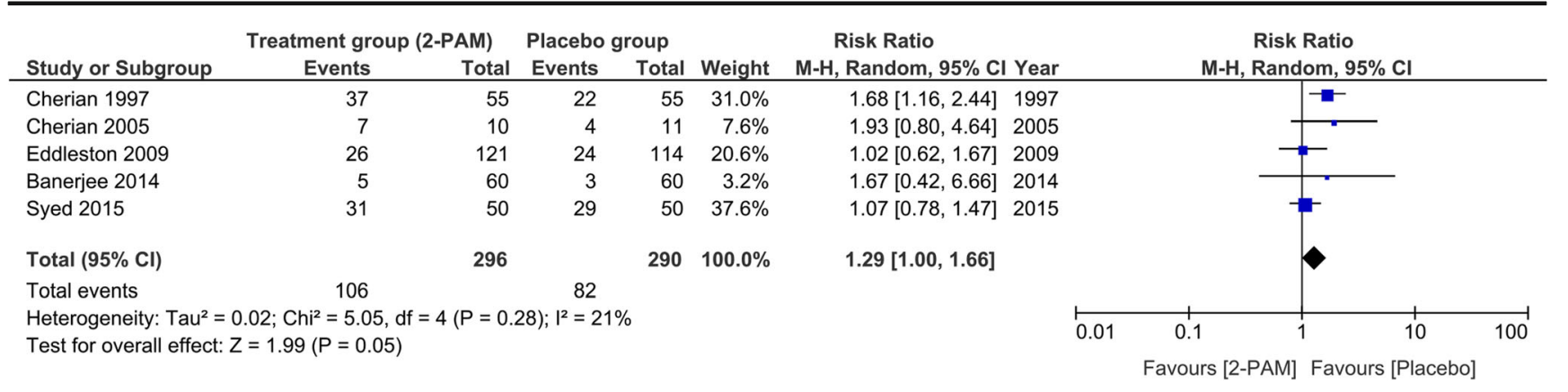

Fig. 4 Need for intubation

methods for allocation concealment. Four studies [21-23, 25] were low risk of bias in performance and detection bias. One study [22] met criteria for high risk of bias in performance and detection due to its open-label design. All of the included studies were low risk of bias in the domains of attrition and selective reporting biases. High risks of other bias were noted in four studies [21, 22, 24, 25] including lack of sample size and power calculation and lack of stopping rule.

\section{Outcomes: Mortality}

Five studies [21-25] reported mortality among 586 patients. The mortality rate among those in the treatment (atropine +2 PAM) group ranged from 1 [22] to $29 \%$ [21] with a weighted prevalence of $24 \%$ (95\% CI 19-29\%). The mortality rate among those in the placebo (atropine without 2-PAM) group ranged from $1 \%$ [22] to $28 \%$ [25] with a weighted prevalence of $15 \%$ (95\% CI 11-20\%). The pooled RR for death was 1.54 (95\% CI 0.92-2.56) indicating no difference in the risk of death between the two groups (Fig. 3). Separate analysis utilizing studies that only included patients with moderate to severe intoxication $[21,22,25]$, did not change the results (pooled RR $=1.82,95 \%$ CI 0.46-7.23).

\section{Outcomes: Rate and Duration of Intubation}

Five studies 21-25 reported the rate of intubation among 586 patients. The risk ratio for intubation ranged from 1.02 [23] to 1.93 [22] with pooled RR of 1.29 (95\% CI 1.00-1.66) indicating a minimally increased intubation risk in the intervention (atropine +2-PAM) group (Fig. 4). This minimal increase in the need for intubation disappeared when we analyzed studies that only included patients with moderate to severe intoxication $[21,22,25]$ as a separate group (pooled $\mathrm{RR}=1.40,95 \%$ CI $0.96-2.03)$.

Three studies $[21,22,25]$ reported the duration of ventilation. The duration of ventilation was not different between the intervention and placebo groups with mean difference of 0.00 (95\% CI - 1.59-1.60) (Fig. 5).

\section{Outcomes: Intermediate Syndrome}

Two studies [21, 25] described the incidence of intermediate syndrome. In both studies, the incidence of intermediate syndrome was higher in the 2-PAM group (20.0 [25] and 65.4\% [21] when compared to the placebo group (18.0 [25] and $34.5 \%$ [21]. The RR of intermediate syndrome ranged from 1.11 [25] to 1.89 [21] with pooled RR of 1.63 (95\% CI 1.012.62 ) indicating a slight increased risk of intermediate syndrome in the treatment group (Fig. 6).

\section{Outcomes: Complications}

Complications were reported in three studies. While Cherian et al. [21] and [22] only reported nosocomial infections, Syed et al. [25] also reported dysrhythmias and noncardiogenic pulmonary edema. The pooled RR for complications was 1.25 (95\% CI 0.85-1.83, Fig. 7).

\section{Limitations}

Limitations to the generalizability of our meta-analysis are based on several issues. Firstly, the available data are primarily from the developing world. Variation in access to critical care units in the developing versus developed world might influence patient

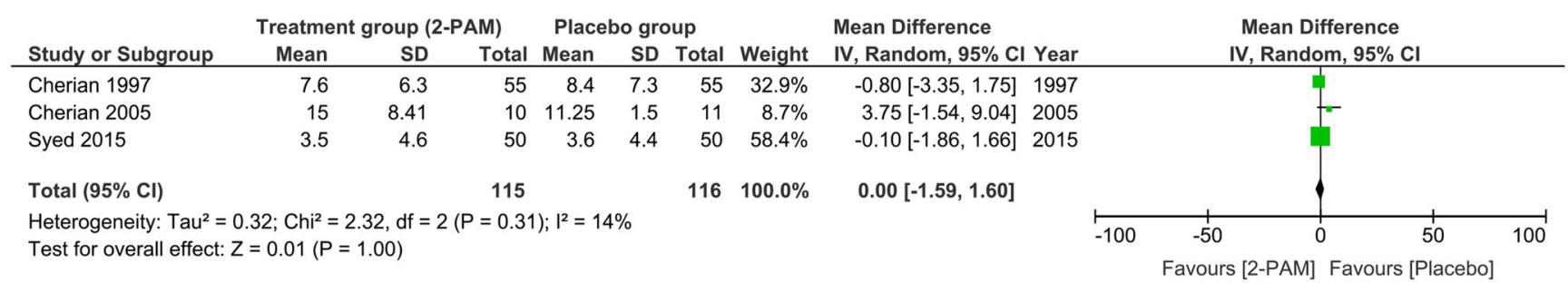

Fig. 5 Duration of ventilation 


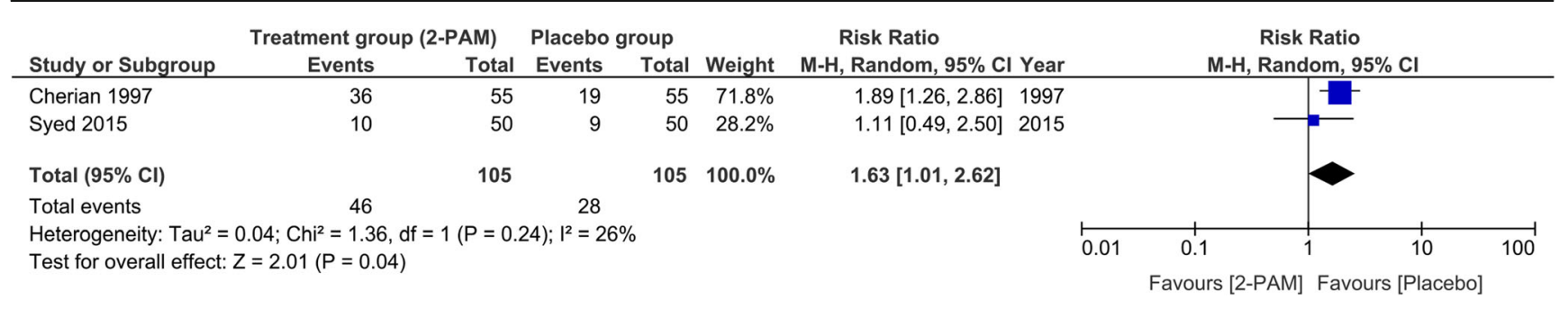

Fig. 6 Intermediate syndrome

outcomes. Additionally, the epidemiology of precisely which chemical agent resulted in the clinical manifestation of OP toxicity is based on local factors of substance accessibility. Typically OPs in the various studies were commercially available pesticides (chlorpyrifos, dimethoate, etc.). These substances are highly regulated and more difficult to obtain in many developed nations. The studies do not necessarily reflect the utility of 2PAM in treating poisoning with other cholinesterase inhibitors such as carbamates (neostigmine, physostigmine, etc.) or military nerve agents (sarin, VX, etc.). It is also possible that some carbamate-poisoned patients were included in the study population; if this subset fares worse with pralidoxime treatment then a type II error may result. Secondly, the studies did not include children. It is unclear to what extent, if any, our conclusions may be extrapolated to pediatric populations. Thirdly, only Englishlanguage studies were included; however, language restriction in systematic reviews and meta-analyses in medicine has not been shown to result in bias [26]. Fourthly, 2-PAM was the only study agent and these data should not be extrapolated to other oximes. Lastly, we did not have access to patient level data and therefore could not account for factors such as age, intoxication severity, and comorbidities.

\section{Discussion}

Based on our meta-analysis of the available studies, the addition of 2-PAM to atropine was not shown to improve outcomes in patients with acute OP poisoning. We used a thorough literature search strategy to minimize selection bias, and identified five studies including a total of 586 adult participants comparing 2-PAM plus atropine to atropine alone for the management of acute OP poisoning. Only RCTs involving direct comparisons of the study agent to placebo were eligible for inclusion. These results support the conclusions of the Cochrane systematic review by Buckley et al. [13] with addition of data from two more recent RCTs [24,25].

The overall quality of the five included studies [21-25] were moderate to high (Fig. 2). All of the eligible trials [21-25] included quantification of patient-oriented outcomes such as mortality, rate of invasive ventilation, and other complications. Mortality is a hard endpoint and four of the studies included blinding of the outcome assessment. Therefore, measurement biases were negligible. There were no patients lost to follow-up, and there was no selective reporting.

Potential confounders to the results of our meta-analysis include variable dosing of 2-PAM across studies (Table 1). Dosing of 2-PAM ranged from approximately 4-12 g per day, with varying durations of therapy. Additionally, whether a patient requires invasive ventilation is a clinical decision and, rate of intubation is therefore potentially biased by subjective physician judgment.

In our meta-analysis, all of the studies included patients who had a history of OP exposure along with the cholinergic toxidrome, which has implications for clinical practice. The concept of an unknown OP agent was addressed in the experimental design, i.e., a cholinergic clinical syndrome-triggered treatment in some patients, not history of exposure to a specific chemical agent alone [21-25]. As a result, when a patient presents with the acute cholinergic toxidrome, identification of the precise chemical cause is not necessary to invoke the results of this meta-analysis. Nonetheless, knowledge of local epidemiology is crucial and care should be taken in a setting that implies exposure to an OP that has not been adequately studied. For example, an urban mass casualty incident may indicate a military or terrorist agent exposure.

Implications for research may be drawn from this metaanalysis as well. Though this systematic review was unable

\begin{tabular}{|c|c|c|c|c|c|}
\hline \multirow[b]{2}{*}{ Study or Subgroup } & \multicolumn{2}{|c|}{ Treatment group (2-PAM) } & \multicolumn{2}{|c|}{ Placebo group } & \multirow[b]{2}{*}{ Weight } \\
\hline & Events & Total & Events & Total & \\
\hline Cherian 1997 & 25 & 55 & 14 & 55 & $31.1 \%$ \\
\hline Cherian 2005 & 4 & 10 & 6 & 11 & $13.9 \%$ \\
\hline Syed 2015 & 35 & 50 & 30 & 50 & $55.0 \%$ \\
\hline Total $(95 \% \mathrm{Cl})$ & & 115 & & 116 & $100.0 \%$ \\
\hline Total events & 64 & & 50 & & \\
\hline \multicolumn{6}{|c|}{$\begin{array}{l}\text { Heterogeneity: } \mathrm{Tau}^{2}=0.05 ; \mathrm{Chi}^{2}=3.29, \mathrm{df}=2(\mathrm{P}=0.19) ; \mathrm{I}^{2}=39 \% \\
\text { Test for }\end{array}$} \\
\hline
\end{tabular}

Risk Ratio M-H, Random, 95\% Cl Year $1.79[1.04,3.06] 1997$ $0.73[0.29,1.86] 2005$ $1.17[0.87,1.56] 2015$

$1.25[0.85,1.83]$

Fig. 7 Complications 
to demonstrate clinical efficacy of 2-PAM in acute OP pesticide toxicity, it is possible that including a larger sample size could conceivably show benefit or harm with 2-PAM. Additionally, data regarding 2-PAM for treatment of OP poisoning in pediatric populations, the developed world, weaponized nerve agent poisoning, and carbamate poisoning are still lacking. Further research is needed to elucidate the use of 2-PAM in these areas. Finally, our meta-analysis only examined the use of the most common oxime, 2-PAM. It is possible that other oximes might be more effective.

Despite the limitations pertaining to the generalizability of the data, we identified important findings regarding the treatment of acute OP poisoning. Our results do not demonstrate a statistically significant difference in patient outcomes between the atropine plus 2-PAM and atropine alone. Therefore, the routine use of 2-PAM in the treatment of organophosphate toxicity is not supported by the currently available data.

Acknowledgements The authors would like to thank Christopher Stewart, senior assistant librarian at SUNY Downstate Medical Center, for his help in formulating the literature search strategy. The authors would like to thank Dr. Nicholas Buckley.

Funding None.

\section{Compliance with Ethical Standards}

Conflict of Interests None.

Previous Presentation None

\section{References}

1. http://www.who.int/gho/publications/world health statistics/2016/ en/ Access date 05/01/2017.

2. World Health Organization The public health impact of pesticides use in agriculture. Geneva, Switzerland: World Health Organization, 1990. http://www.who.int/iris/handle/10665/39772 Access date 05/01/2017.

3. Jeyaratnam J, de Alwis Seneviratne RS, Copplestone JF. Survey of pesticide poisoning in Sri Lanka. Bull World Health Organ. 1982;60(4):615-9.

4. Jeyaratnam J, Lun KC, Phoon WO. Survey of acute pesticide poisoning among agricultural workers in four Asian countries. Bull World Health Organ. 1987;65(4):521-7.

5. http://news.bbc.co.uk/onthisday/hi/dates/stories/march/16/newsid 4304000/4304853.stm Access date 05/01/2017.

6. Wright RB. Dreams and shadows: the future of the Middle East. New York: Penguin; 2009.

7. Sellström, Åke; Cairns, Scott; Barbeschi, Maurizio. Report of the United Nations Mission to investigate allegations of the use of chemical weapons in the Syrian Arab Republic on the alleged use of chemical weapons in the Ghouta area of Damascus on 21 August 2013. United Nations. Access date 05/01/2017.

8. Gladstone, Rick; Sengupta, Somini. "Missed opportunity in Syria haunts U.N. official" The New York Times. http://www.nytimes. com/2013/10/03/world/middleeast/syria.html Access date 05/01/ 2017.

9. Dewan A. 'Incontrovertible' evidence Sarin used in Syria, watchdog says. CNN. 2017; available from http://www.cnn.com/2017/ 04/20/middleeast/syria-chemical-attack-sarin-opcw/ Access date $05 / 01 / 2017$

10. https://www.britannica.com/event/Tokyo-subway-attack-of-1995 Access date 05/01/2017.

11. http://www.cnn.com/2017/02/23/asia/kim-jong-nam-vx-nerveagent/ Access date 05/01/2017.

12. Worek F, Kirchner T, Backer M, Szinicz L. Reactivation by various oximes of human erythrocyte acetylcholinesterase inhibited by different organophosphorus compounds. Arch Toxicol. 1996;70:497503.

13. Buckley NA, Eddleston M, Li Y, Bevan M, Robertson J. Oximes for acute organophosphate pesticide poisoning. Cochrane Database of Systematic Reviews 2011.

14. Bhalla A, Singh S. Why do the results of studies on the effectiveness of pralidoxime for treatment of organophosphate poisoning vary? Asia Pacific Journal of Medical Toxicology. 2015;4:116-22.

15. Peter JV, Moran JL, Graham P. Oxime therapy and outcomes in human organophosphate poisoning: an evaluation using metaanalytic techniques. Crit Care Med. 2006;34:502-10.

16. Rahimi R, Nikfar S, Abdollahi M. Increased morbidity and mortality in acute human organophosphate-poisoned patients treated by oximes: a meta-analysis of clinical trials. Hum Exp Toxicol. 2006;25:157-62.

17. Shamseer Larissa, Moher David, Clarke Mike, Ghersi Davina, Liberati Alessandro, Petticrew Mark et al. Preferred reporting items for systematic review and meta-analysis protocols (PRISMA-P) 2015: elaboration and explanation BMJ 2015; 349:g7647.

18. https://www.crd.york.ac.uk/PROSPERO. Accessed date 05/01/ 2017.

19. Review Manager (RevMan) [Computer program]. Version 5, vol. 3. Copenhagen: The Nordic Cochrane Centre, The Cochrane Collaboration; 2014.

20. http://handbook.cochrane.org/chapter_8/table_8_5_a_the cochrane_collaborations_tool_for_assessing.htm. Accessed date 4 . 18.2017.

21. Cherian AM, Peter JV, Samuel J, Jaydevan R, Peter S, Joel S, et al. Effectiveness of P2AM (PAM-pralidoxime) in the treatment of organophosphorus poisoning. A randomised, double blind placebo controlled trial. Journal of Association of Physicians of India. 1997:45:22-4.

22. Cherian MA, Roshini C, Visalakshi J, Jeyaseelan L, Cherian AM. Biochemical and clinical profile after organophosphorus poisoning - a placebo-controlled trial using pralidoxime. Journal of Association of Physicians of India. 2005;53:427-31.

23. Eddleston M, Eyer P, Worek F, et al. Pralidoxime in acute organophosphorus insecticide poisoning - a randomised controlled trial. PLoS Med. 2009;6(6)

24. Banerjee I, Tripathi SK, Sinha Roy AA. Study on comparative evaluation of add-on pralidoxime therapy over atropine in the management of organophosphorus poisoning in a tertiary care hospital. JK Sci. 2011;13:65-9.

25. Syed S, Gurcoo SA, Farooqui A, Nisa W, Sofi K, Wani TMI. The World Health Organization-recommended dose of pralidoxime effective in the treatment of organophosphorus poisoning? A randomized, double-blinded and placebo-controlled trial. Saudi J Anaesth. 2015;9:49-54.

26. Morrison A, Polisena J, Husereau D, et al. The effect of Englishlanguage restriction on systematic review-based meta-analyses: a systematic review of empirical studies. Int J Technol Assess Health Care. 2012;28:138-44. 